\title{
Effects of Using of Contemporary Art in High Education on Students Metacognitive Awareness
}

\author{
Vasya Delibaltova \\ Faculty of Education, Sofia University “St. Kliment Ohridski”, Republic of Bulgaria
}

Copyright $(2016$ by authors, all rights reserved. Authors agree that this article remains permanently open access under the terms of the Creative Commons Attribution License 4.0 International License

\begin{abstract}
The aim of this study was to determine the effects of the use of contemporary art in High Education on Students' Metacognitive Awareness from students' point of view after their involvement in specially designed activities. The learning context was created under the main thesis that metacognitive development can be supported by the creation of didactic situations, in which three different relations are blended - with the environment, with the others, and with oneself, based on the combination of different spaces. This thesis here was interpreted under contemporary art. The study was carried out with three groups of students from different specialty in period between 2014 and 2015. Quantitative data was used for the base of the analyses. The data was obtained using the Metacognitive Awareness Inventory which was developed by Schraw and R. Dennison [18]. As a result it was outlined that the main effect of using contemporary art in context of this research is the regulation of cognition.
\end{abstract}

Keywords Design of Educational Activities, Metacognition, Contemporary Art

\section{Introduction}

For the last 300 years, on the verge of every two centuries the humans ask themselves numerous questions related to the world and their existence in it. The different concept of education today also reflects the search of the answers to these questions and it allows the formation of a flexible and adaptive person, capable of dealing with the challenges of time and fast developing information. One of the possible solutions is finding an approach, which increases the effectiveness of learning and provokes doing plenty of research (National Research Council, [17]). As a result, the perspective related to the research of metacognitive development of learners stands out explicitly like a factor for the increase of this effectiveness (Lefrancois [14]; Slavin [21]; Holodnaya [12,13]; Akturk, Sahin [1]; Cubukcu, [2]; Desoete [6]; Fariha Gula, Shumaila Shehzad, [7]; Hacker,
Dunlosky, Graesser, [11] ). Despite the different approaches and solutions, today it is unanimously accepted that every educational model related to the development of students' thinking inevitably involves concern about supporting the "thinking about thinking". To some extent this leads to the reformulation of Flavel's basic question - Can metacognitive development be assisted? Into how could this be done?

The time and the available research showed the complexity of finding a commonly accepted answer. Part of the problem is predetermined by the absence of consensus on what we call metacognition. As it is noted:"Metacognition was originally referred to as the knowledge about and regulation of one's cognitive activities in learning processes" (Flavell, 1979; Brown, 1978). Under the umbrella of this inclusive definition a proliferation of metacognitive terms has unfolded through the years." [22: 3-4]

This abundance of terms provokes other questions [4]:

- is it possible to use knowledge and cognition (Holodnaya [12,13]) and respectively meta knowledge and metacognition as synonyms (Merdjanova $[15,16]$ )

- can we distinguish between metacognition and cognition (Akturk, Sahin, [1], Veenman,Van Hout-Wolters, Afflerbach, [22])

- what is the relation between metacognition and self-regulation (Fox, Riconscente [10]; Schunk [20], Yankulova [24])

- is metacognition general or it depends on the field of application (Hacker, Dunlosky, Graesser, [11])

We can outline a scientific field, full of unknowns, each of which is worth being researched independently. The issue becomes even more complicated due to the fact that the question whether metacognition could be developed purposefully in and by teaching/ learning process is under discussion. So is the question if this could be done by traditional approaches or rather by methods similar to constructivism. What stands out is the necessity of doing research in real educational practices.

From our point of view, an interesting perspective of such a study is presented in Fox's and Riconscente's work:

"Metacognition and self-regulation ground your conscious 
experience of yourself as knower and actor. With James, you are at home in the Self, with Piaget, you are at home in the world and with others, and with Vygotsky, you are at home in language. Each one provides a way of considering what it means to "be at home" as a human being, and centers human development around a different core outcome. These different developmental goals imply differences in the potential aim of education. For James, education might best foster individuality and self-fulfillment. For Piaget, collaboration coupled with autonomy might be the goal. For Vygotsky, education might support cultural progress, through mastery of existing cultural tools and openness to the development and use of new modes of language activities and new tools. How one is aligned in terms of what is taken as fundamental in the relation of subject and object when considering metacognition and self-regulation has theoretical, methodological, and educational implications." [10: 387-388]

Fox's conclusions confirm our concept that the assistance of metacognitive development could be possible if students are involved in relations and events which are part of a wider learning environment. For us creating such an environment is achievable through the use of contemporary art in university educational practices.

The grounds for this are found in the concept that if: "The viewer enters the picture of old art indirectly, conditionally, with thought and imagination, it is read like a book - it is "text"-narrative, whereas contemporary art creates "live" pictures and the viewer enters them directly, he is present, participates and inhabits them physically."[5] The Viewer may become an Artist and the Artist may take the role of the Viewer in order to experience catharsis, to interpret and reinterpret reality, to know themselves and the others.

Having these characteristics, contemporary art allows plenty of didactic interpretations because it creates conditions to creation of learning activities because we can find:

a) "go into" the happening directly and indirectly;

b) alternate the imaginative with the experience;

c) exchange the roles of the Artist and the Viewer;

d) study reality in different contexts;

e) get to know the others;

f) recognize and love themselves.

In a learning environment, constructed by using contemporary art, the relation James-Piaget-Vygotsky could be realized practically - „,...James's perspective on metacognition and self-regulation is aligned with the Self, Piaget's with the other and object, and Vygotsky's with the medium or agency of language." [10:373]

From this point of view the thesis that you can learn through art is well-founded. However, not like an amusing game but rather like catharsis, understanding, communication. This is not entertaining learning but conscious and unconscious building of connections until wholes are created (Delibaltova, Morozova, [5])

A similar assertion could be found with P.Venäläinen,
P.[23: 458]. According to his main thesis, based mostly on Nicolas Bouttiaud's work, contemporary art pretends to be a form of life and action in the existing reality as a result of an endless sequence of relations between individuals and the surrounding world. This starting point allows him to make his own conception in which he presents contemporary art like a didactic dialogue - with its own aims and methods related to encouraging learning and finally understanding the world, the others and oneself. However, what is important is not the preliminary aims but the process, which is always educational, [23: 459]. A similar approach, according to the quoted author, gives the freedom to create your own ways when seeing art and every time you can start from a different place and try to achieve different goals - you can improve "the relations" with yourself, enjoy yourself, feel satisfied with a specific work of art or provoke learning.

The aim of this article is to present a study, which is part of bigger research oriented towards creating an entire model of using contemporary art as the basis of inventing didactic situations which support the metacognitive development of learners. It is based on the adopted thesis that metacognitive development can be supported by creating didactic situations related to the environment, to the others and to oneself, using different spaces, different levels of thinking and reciprocity. Presumably, this involves the creation of a learning context, which can integrate different points of view (yours and other people's) and environments (the museum, the university, art and reality). Thus we have the hypothesis that learning context influences different components of metacognition differentially.

The whole study is carried out within a five-year period and involves research of the effect of different learning context activities on students' metacognitive awareness. The final stage of this study is the research of students ` point of view.

The realization of the study presumes the answers to two questions, which are secondary in the research as a whole, but also have their own value regarding their relative self-sufficiency:

- How are the peculiarities of the museum-university model of interaction projected on specific activities while using contemporary art?

- What is the students ' point of view about the effects of museum activities on their metacognitive awareness?

These questions lead to the formulation of two aims at this stage. The first and the most important one is to study the opinion of the students (who are experts) of the influence of the constructed interaction on the different categories of metacognition. However, obtaining this data requires the approbation of a constructed version of the relation museum-university, which provided the possibility to outline some perspectives for interaction at this level as well.

The aim of this study was to determine the effects of using contemporary art in High Education on students' Metacognitive Awareness from students' point of view after 
their involvement in specially designed activities.

\section{Methodology}

Our sample consisted of $283^{\text {rd }}$ and $4^{\text {th }}$ year students ( 4 boys and 24 girls), aged between 22 and 26, studying Pedagogy, Informal Education and Social Work at Sofia University. The students study two elective courses (16 do one of the courses and 10 - the other one). All of them participate in the study voluntarily.

The answer to the first research question is based on the elaborated and approbated version of the used invariants at school, which were realized at the National Art Gallery and especially the retrospective exhibition of Brian Dailey: "Declassified: Unraveling a Paradox" and the Museum of Contemporary Art and the exhibition "SPACE AUDIENCE" of Vito Valentinov, Simeon Simeonov, Arch. Milena Metalkova-Markova, Adel Lemoan and others.

The specific task took place in several stages. Firstly, the students had to choose a problem in the context of the course and to give the arguments for their position related to it or suggest possible solutions. Secondly, after getting aware of the exposition they had to outline the main problems presented from the author's point of view. The next stage was the discussion of the means with which the author defended his position and the assessment of their authenticity, attractivity and reliability. Finally, the students had to develop their own idea based on the main genres of contemporary art through which they had to "present" and support their initial thesis, using means of art. The reproduced authors' ideas are exhibited in the area of the university or if it is possible in a museum with the participation of an Artist/Curator. During the last stage conclusions at metacognitive and content levels are drawn.

The pilot approbations took place in April and May 2014 when students studying Pedagogy and Informal Education participated in Architectural building of the social atom (work of D. Morozova, pedagogical adaptation of $\mathrm{V}$. Delibaltova). The real study was realized between September 2014 and March 2015.

Metacognitive Awareness Inventory (MAI) by G. Schraw, R. Dennison [18] was used as the main tool for collecting data. The inventory is used in an unusual way in order to collect the students' opinions like experts - the instruction has been changed. It says:" Dear students, please answer with yes or no which of the following statements are true or false for you. Mark with X those which influenced your work in the current course for the last weeks".

The conception on which the tool is built is completely accepted.

It is known that the tool is based on the belief that metacognition is a phenomenon, general by nature but multi-dimensional in its essence. (G. Schraw $[18,19])$. It can conditionally be divided into knowledge about cognition and regulation of cognition. Knowledge about cognition includes declarative knowledge, procedural knowledge and knowledge about conditions.

Declarative knowledge involves factual knowledge which learners need in order to work on a specific topic as well as to know their own intellectual abilities, their strengths and weaknesses.

Procedural knowledge is related to the answer to the question "how" we have to do things and it involves not only using knowledge to achieve the final aim but also knowledge about the way of applying cognitive strategies.

Conditional knowledge involves the answers to two questions - "why" and "when" we have to use declarative and procedural knowledge. It must be stated in what circumstances some methods work and when other approached must be used.

On the other hand, the regulation of cognition involves planning, comprehension monitoring, information management strategies, debugging strategies and evaluation.

Planning is related to the ability to set goals and distribute the available resources during the learning process. The information management strategies are related to the ability to organize, develop, generalize, focus selectively. Comprehension monitoring is focused on the effective use of strategies and learning assessment and the results of it are used for the basis on which the debugging strategies are made. The analysis of the realization and effectiveness of the strategies after a learning module is related to evaluation.

A series of statements is developed for each of these fields, as follows:

a. declarative knowledge - 5, 10,12,16,17, 20,32,46;

b. procedural knowledge - 3, 14, 27, 33;

c. conditional knowledge - 15,18, 26, 29, 35;

d. planning $-4,6,8,22,23,42,45$;

e. monitoring - 1, 2, 11, 21, 28, 34,49;

f. strategies of information management $-9,13,31,37$, $39,41,43,47,48$;

g. debugging strategies- $25,40,44,51,52$;

h. evaluation $-7,19,24,36,38,50$.

In order to be used correctly, the tool has been translated from English into Bulgarian and into Russian, from Bulgarian into English and from Russian into Bulgarian by three translators. The final version of the questionnaire is a product which has been edited several times.

\section{Research Results and Discussion}

The results presents students' point of view after the approbation of the constructed didactic situation. They are considered both at individual level and at the respondents' level in general.

As it could be seen from the Table1, according to the frequency of choices, the component categories and the corresponding statements are as follows: 
Table 1. Student views related to component categories

\begin{tabular}{|c|c|c|}
\hline Component categories & Sentences & $\mathrm{f}$ \\
\hline Declarative knowledge & $\begin{array}{l}\text { I understand my intellectual strengths and weaknesses } \\
\text { I know what kind of information is most important to learn } \\
\text { I am good at organizing information. } \\
\text { I know what the teacher expects me to learn } \\
\text { I am good at remembering information. } \\
\text { I have control over how well I learn } \\
\text { I am a good judge of how well I understand something. } \\
\text { I learn more when I am interested in the topic }\end{array}$ & $\begin{array}{l}8 \\
1 \\
4 \\
1 \\
1 \\
0 \\
1 \\
9\end{array}$ \\
\hline $\begin{array}{l}\text { Procedural } \\
\text { knowledge }\end{array}$ & $\begin{array}{l}\text { I try to use strategies that have worked in the past. } \\
\text { I have a specific purpose for each strategy I use. } \\
\text { I am aware of what strategies I use when I study. } \\
\text { I find myself using helpful learning strategies automatically }\end{array}$ & $\begin{array}{l}1 \\
4 \\
2 \\
1\end{array}$ \\
\hline $\begin{array}{l}\text { Conditional } \\
\text { knowledge }\end{array}$ & $\begin{array}{l}\text { I learn best when I know something about the topic. } \\
\text { I use different learning strategies depending on the situation. } \\
\text { I can motivate myself to learn when I need to } \\
\text { I use my intellectual strengths to compensate for my weaknesses. } \\
\text { I know when each strategy I use will be most effective. }\end{array}$ & $\begin{array}{l}2 \\
8 \\
2 \\
8 \\
2\end{array}$ \\
\hline Planning & $\begin{array}{l}\text { I pace myself while learning in order to have enough time } \\
\text { I think about what I really need to learn before I begin a task. } \\
\text { I set specific goals before I begin a task. } \\
\text { I ask myself questions about the material before I begin. } \\
\text { I think of several ways to solve a problem and choose the best one. } \\
\text { I read instructions carefully before I begin a task. } \\
\text { I organize my time to best accomplish my goals. }\end{array}$ & $\begin{array}{l}2 \\
8 \\
3 \\
1 \\
4 \\
8 \\
2\end{array}$ \\
\hline Monitoring & $\begin{array}{l}\text { I ask myself periodically if I am meeting my goals. } \\
\text { I consider several alternatives to a problem before I answer. } \\
\text { I ask myself if I have considered all options when solving a problem. } \\
\text { I periodically review to help me understand important relationships } \\
\text { I find myself analyzing the usefulness of strategies while study. } \\
\text { I find myself pausing regularly to check my comprehension } \\
\text { I ask myself questions about how well I am doing while I am } \\
\text { learning something new. }\end{array}$ & $\begin{array}{l}2 \\
8 \\
3 \\
1 \\
8 \\
4 \\
4\end{array}$ \\
\hline $\begin{array}{l}\text { Strategies of } \\
\text { information } \\
\text { management }\end{array}$ & $\begin{array}{l}\text { I slow down when I encounter important information. } \\
\text { I consciously focus my attention on important information. } \\
\text { I focus on the meaning and significance of new information. } \\
\text { I create my own examples to make information more meaningful. } \\
\text { I draw pictures or diagrams to help me understand while learning. } \\
\text { I try to translate new information into my own words. } \\
\text { I use the organizational structure of the text to help me learn. } \\
\text { I ask myself if what I'm reading is related to what I already know. } \\
\text { I try to break studying down into smaller steps. } \\
\text { I focus on overall meaning rather than specifics. }\end{array}$ & $\begin{array}{l}3 \\
1 \\
14 \\
2 \\
2 \\
2 \\
2 \\
2 \\
2 \\
2\end{array}$ \\
\hline $\begin{array}{l}\text { Debugging } \\
\text { strategies }\end{array}$ & $\begin{array}{l}\text { I ask others for help when I don't understand something. } \\
\text { I change strategies when I fail to understand. } \\
\text { I reevaluate my assumptions when I get confused. } \\
\text { I stop and go back over new information that is not clear. } \\
\text { I stop and reread when I get confused. }\end{array}$ & $\begin{array}{c}13 \\
1 \\
1 \\
2 \\
4\end{array}$ \\
\hline Evaluation & $\begin{array}{l}\text { I know how well I did once I finish a test. } \\
\text { I ask myself if there was an easier way to do things after I finish a task. } \\
\text { I summarize what I've learned after I finish. } \\
\text { I ask myself how well I accomplish my goals once I'm finished. } \\
\text { I ask myself if I have considered all options after I solve a problem. } \\
\text { I ask myself if I learned as much as I could have once I finish a task. }\end{array}$ & $\begin{array}{l}2 \\
1 \\
8 \\
2 \\
3 \\
3\end{array}$ \\
\hline
\end{tabular}


The presented data shows that as regards the declarative knowledge, the opinion of the students on the effect of the constructed situations varies widely with respect to the separate statements - from 0 to 9 choices. According to the respondents the different contexts in which the activities were projected and implemented, the new situation in which the students are put and the level of thinking on which they work, do not influence the control over the quality of learning but affects positively the awareness of the role of the interest. Against this background a certain contradiction stands out - a relatively high number of choices on the awareness of understanding of intellectual strengths and weaknesses and a low number of choices regarding concrete skills.

To a certain extent the commented results correspond to the only choice which was made in terms of the realization of the attempts at resorting to strategies which had worked earlier and the automatic use of successful strategies. Probably the activities which have been implemented here are principally different from the previous experience of the students and therefore new strategies for coping with the situation have been sought. A similar connection could be traced out also in the effect on the realization of the use of the strengths for overcoming the weaknesses. Much greater, according to the students, is the influence of the constructed activities on the realization of the interrelation between working strategies and situation specifics of and the use of different learning techniques.

These results allow us to assert that as a whole regarding the knowledge on the cognition, the data reveals the greater effect of the constructed activities on the knowledge about the conditions and a lesser effect on the declarative knowledge.

The new situation has probably affected the accents in the planning as well. It is obvious that the respondents see a stringer the influence on a big share of the statements directly connected with the planning of the problem-solving activity. The timing is an exception in this trend. A possible explanation of this data could be found in the unusual character of the tasks in the context of the academic learning environment.

The specifics of learning through problem-solving are clear in the monitoring as well, where a certain though not very strong trend towards increase in the frequency of choices is visible. In the conditions of the constructed tasks, according to the students, the conscious searching for different solutions and the analysis of working strategies are largely stimulated.

Half of the students however have selected the realization of the meaning and the significance of new information as an obvious effect of the chosen didactic approach. This result is interesting when compared with the only choice regarding the conscious attention to important information. Does the novelty make attention shift from the importance of the information?

The differences regarding the error elimination strategies are also substantial. For half of the students teamwork seems to have a significant effect on the realization of the need to ask for help in problem solving. Only for one the effect is sought on the realization of the degree to which the activity affects the change of the strategy in case of a misunderstanding. The same result is registered regarding the reassessment in problem-solving difficulties.

According to the respondents the projected activities are a good basis for influencing the realization of the summarization of the work done and don't create conditions for an evaluation of the possibility for an easier solution of the task.

If we move to the level of analysis of the statements as a whole we must point out that the categories are arranged as follows:

a. Statement 30 is first with 14 choices, it is a key statement for the strategy of information management - "I focus on the meaning and significance of new information"

b. This result corresponds to the data, received for statement 25 and the debugging strategies- "I ask others for help when I don't understand something". This statement is chosen by 13 students and comes second.

c. Statement 46 is third, it is chosen by 9 people - "I learn more, when I am interested in the topic", it is related to declarative knowledge.

d. Eight statements are fourth, they are chosen by 8 students - statement 2 - "I consider several alternatives to solve a problem before I answer" monitoring; statement 5- „I understand my intellectual strengths and weaknesses" - declarative knowledge; statement 6- „I think about what I really need to learn before I begin a task"- planning ; statement 18 - „I use different learning strategies depending on the situation"-conditional knowledge; statement 24 "I summarize what I've learned after I finish” - evaluation; statement 28- „I find myself analyzing the usefulness of strategies while I study“ -monitoring; statement 29- „I use my intellectual strengths to compensate for my weaknesses" - conditional knowledge and statement 42 - „I read instructions carefully before I begin a task" - planning.

e. One statement isn't chosen by any of the students 20 - "I have control over how well I learn"- related to declarative knowledge.

Provided that the conclusions drawn above are valid for the group of the respondents, it is obvious that only in one subcategory there aren't any statements that haven't been chosen - declarative knowledge. The data shows that as a whole in the students think that the approbated approach is more useful for the regulation of cognition: strategies for information management, monitoring and debugging strategies.

As far as the projected activities have been implemented 
in an open learning environment - part of the activities have been carried out at an art museum and part at the university the results should be considered and analyzed bearing in mind the effect of the context on the metacognitive realization. For comparison's purposes it is important to point out that the collected results correspond to data from previous surveys among high school students [4]. The results from these surveys show that in projected activities based on the use of modern art, which are implemented in a different learning context, we have the strongest effect on the subcategories of the regulation of cognition - a result which we received when studying the viewpoint of university students too.

At the same time the study provokes a series of questions, regarding the relation between metacognitive awareness and subject specific knowledge and skills. Of a particular interest is the relation between subject knowledge and skills and declarative knowledge. Based on our unpresuming research [4], it seems that metacognitive development influences the ability for learning but not the result - motivation and corresponding behavior are also required for it. A number of research works show that good students have a high metacognitive level, whereas the opposite seems not to be always true.

The facts which show some differences in the results, regarding age, are interesting. The question is - are they dominated by age or rather we could talk about a complicated interaction between different factors, one of which is related to age characteristics of students. Having in mind the results of this study, finding the answer to this question in the conditions of the real daily educational practice and its research does not seem possible. Undoubtedly, the answer requires the „partnership" of many specialists and research in many contexts.

\section{Conclusions}

This survey was planned and carried out with the aim of studying the possibility to support the learners' metacognitive awareness by means of a didactic interpretation of contemporary art as a learning environment. Of special scientific interest was the effect of the activity through the eyes of the students who took part in previously drawn up and approbated activities carried out in an open creative environment standing between the museum and the university. The received results, in line with our previous surveys among high school students, reveal a couple of perspective, in our opinion, research lines:

- the relation between school age and educational degree on the one hand and the metacognitive knowledge on the other

- the effect of the subject-specific knowledge on the metacognitive knowledge.

The longstanding work on our studies in this scientific field, have given us many proofs of the fact that the study of the abovementioned relations and interrelations in the environment of the everyday educational practice only isn't possible. The achieving of significant results undoubtedly calls for partnerships with many experts and research in many contexts. The data from our studies makes us believe that modern art is an interesting and fruitful starting point for the implementation of such studies.

\section{REFERENCES}

[1] Akturк ,A., Sahin, I. Literature Review on Metacognition and its Measurement -Procedia Social and Behavioral Sciences 15, 3731-3736., 2011.

[2] Cubukcu F. Metacognition in the classroom. Procedia Social and Behavioral Sciences 1, 559-563., 2009.

[3] Delibaltova, V. Museum, Education. Metacognition. UP "St. Kliment Ohridski“"Sofia. 2015.

[4] Delibaltova, V. Metacognitive development in context of museum and school education. Dis. Sofia. 2015.

[5] Delibaltova, V., Morozova, D. Two Modern Answers to the Question: Can you learn through Contemporary Art Pedagogy, V.87, N 2. 2015.

[6] Desoete,A., The Enigma of Matematical Learning Disabilities: Metacognition or STICORDI, That's the Question. Handbook of Metacognition in Education. N.Y. 2009.

[7] Fariha Gula, Shumaila Shehzad Relationship between metacognition, goal orientation and academic achievement -Procedia - Social and Behavioral Sciences 47, 1864 1868.2012.

[8] Fenichel, M, H. Schweingruber, Surrounded by Science: Learning Science in Informal Environments. 2010.

[9] Flavel, J. Metacognition and Cognitive Monitoring A New Area of Cognitive-Developmental Inquiry -American psychologist, October, 906-911.1979.

[10] Fox, E. Riconscente, M Metacognition and Self-Regulation in James, Piaget, and Vygotsky Educ Psychol Rev. 20:373-389. 2008.

[11] Hacker, D., Dunlosky, J., Graesser, J. (Ed.) Handbook of Metacognition in Education. N.Y., London.2009.

[12] Holodnaya, M. Psychology of intellect: paradoxes of research. Tomsk University, Moscow, Tomsk, B., 1997.

[13] Holodnaya, M., Cognitive styles. About the nature of the individual mind. Moscow, 2004.

[14] Lefrancois, G. Psychology for teaching. „OLMA-PRESS“. M., 2005.

[15] Merdjanova, Y. Pentalogiya. Petekston, S., 2010.

[16] Merdjanova, Y. Basic methodological approaches to transversal competences. Just $6+$. "St.. Kl. Ohridski ", Sofia, 2014.

[17] National Research Council Learning science in informal environments: People, places, and pursuits. Committee on 
Learning Science in Informal Environments. P. Bell, B.Lewenstein, A. W. Shouse \& M. A. Feder (Eds.), Board on Science Education, Center for Education, Division of Behavioral and Social Sciences and Education. Washington, DC: The National Academies Press. 2009. http://www.nap.edu/openbook.php?record id=12190

[18] Schraw, G., R. Dennison. Assessing Metacognitive Awareness. - Contemporary Educational Psychology, 19. 1994.

[19] Schraw, G. Promoting general metacognitive awareness Instructional Science 26: 113-125. 1998.

[20] Schunk, D. Metacognition, Self-Regulation, and
Self-Regulated Learning: Research Recommendations - Educ Psychol Rev 20:463-467.2008.

[21] Slavin, R. Educational Psychology: Theory and Practice, Sixth edition, S., 2004.

[22] Veenman, M, Van Hout-Wolters, B., Afflerbach P Metacognition and learning: conceptual and methodological considerations - Metacognition Learning 1: 3-14, 2006.

[23] Venäläinen, P. Contemporary art as a learning experienceProcedia - Social and Behavioral Sciences 45, 457 465.2012 .

[24] Yankulova, Y. Pedagogical psychology. Paradigma, S., 2012. 